\title{
Chega de etnografia! A educação da atenção como propósito da antropologia*
}

\author{
That's enough about ethnography! An education of attention \\ as purpose of anthropology
}

\section{Basta de Etnografía! La educación la atención es el propósito de la antropología}

\author{
TIM INGOLD**
}

$\diamond$

\begin{abstract}
RESUMO
$\mathrm{Na}$ antropologia e em outras disciplinas, "etnografia" tornou-se um termo tão sobreutilizado a ponto de ter perdido boa parte do seu sentido. Argumenta-se que atribuir "etnograficidade" aos encontros com aqueles entre os quais se realiza a pesquisa - e ao trabalho de campo de modo geral - é colocar em risco o compromisso ontológico e o propósito educacional da antropologia enquanto disciplina, bem como da sua principal maneira de trabalhar, a observação participante. Também significa reproduzir uma distinção perniciosa entre aqueles com os quais se estuda e se aprende dentro e fora da academia, respectivamente. É essa obsessão da antropologia com a etnografia que tem, mais que qualquer outra coisa, solapado a sua voz pública. Para recuperá-la, deve-se reafirmar o seu valor enquanto disciplina orientada para o futuro, dedicada a recompor a ruptura entre imaginação e vida real.
\end{abstract}

Palavras-chave: Correspondência. Educação. Etnografia. Trabalho de campo. Método. Participação observante. Teoria.

\begin{abstract}
In anthropology and other disciplines, "ethnography" has become so over-used a term that it has lost much of its meaning. It is argued that attributing "ethnography" to encounters with those among whom the research is done - and field work in general - is to jeopardize the ontological commitment and educational purpose of anthropology as a discipline, as well as its main way of working, participant observation. It also means reproducing a pernicious distinction between those with whom one studies and learns in and out of academia, respectively. It is this obsession of anthropology with ethnography that has, more than anything else, undermined its public voice. To recover it, one must reaffirm its value as a future-oriented discipline, dedicated to reshaping the rupture between imagination and real life.
\end{abstract}

Keywords: Correspondence. Education. Ethnography. Fieldwork. Method. Observant participation. Theory.

\section{RESUMEN}

En la antropología y otras disciplinas, "etnografía" se ha convertido en un término usado en exceso por lo que se han perdido gran parte de su significado. Se argumenta que asignan "etnograficidade" para reunirse con aquellos con los que se lleva a cabo investigaciones - y trabajo de campo en general - está poniendo en riesgo el compromiso ontológico y la finalidad educativa de la antropología como disciplina, así como su principal forma de trabajar, la observación participante. También significa jugar una distinción perniciosa entre aquellos con los que estudiar y aprender dentro y fuera de la academia, respectivamente. Es esta obsesión de la antropología y la etnografía que tiene, más que cualquier otra cosa, socavado su voz pública. Para recuperarlo, se debe reafirmar su valor como una disciplina orientada hacia el futuro, dedicado a recuperarse de la ruptura entre la imaginación y la vida real.

Palabras clave: Correspondencia. Educación. Etnografia. Trabajo de campo. Método. la participación de observadores. Teoria.

\footnotetext{
*Artigo originalmente publicado em inglês, com tradução autorizada pelo autor. INGOLD, Tim. That's enough about ethnography! Hau: Journal of Ethnographic Theory, v. 4, n. 1, p.383-395, 2014 (licensed under the Creative Commons | (C) Tim Ingold. ISSN 2049-1115 [on-line]. http://dx.doi. org/10.14318/hau4.1.021).

**Doutor em Antropologia. Professor na Universidade de Aberdeen, Escócia. E-mail: <tim.ingold@abdn.ac.uk>.
} 


\section{EXPLICANDO O QUE SE QUER DIZER}

"Etnográfico" tem sido o termo mais abusado na disciplina antropológica. É difícil dizer exatamente quando este se desprendeu de suas amarras originais, ou quais as razões para a sua proliferação subsequente. Essas razões são sem dúvida complexas e poderiam ser tema de um estudo histórico em separado. Neste artigo, a preocupação é mais prospectiva do que retrospectiva. Pois se acredita que esse uso excessivo tem sido nocivo à antropologia e a tem paralisado, enquanto outros campos de estudo avançam e têm impedido essa disciplina de ter o impacto no mundo que merece e do qual o este urgentemente precisa. E porque essa causa é urgente, não se abstém da polêmica. $\mathrm{O}$ teor do que segue é deliberadamente parcial. Chega de equivocação, de obscurantismo acadêmico e da presunção que faz do projeto da antropologia o estudo do seu próprio modo de funcionamento. Uma disciplina confinada ao teatro das suas próprias preocupações não tem para onde ir. Nessa espiral descendente rumo à irrelevância, a antropologia não tem ninguém a culpar além de si mesma.

O propósito não é extinguir a etnografia, nem expurgála da consciência antropológica. Tampouco se subestima sua importância, ou as demandas complexas que coloca para aqueles que a praticam. Preocupa-se, antes, com estreitar seu foco para que, quando perguntarem, de boafé, o que ela significa, possa se responder com precisão e convicção. Só assim, argumenta-se, pode-se protegê-la da inflação que tem ameaçado desvalorizar seu câmbio a ponto de comprometer a empreitada como um todo. Pois não é apenas na antropologia que a etnografia está à solta. Acredita-se que se fala pela maioria dos colegas antropólogos, quando se denuncia o abuso do termo, que tornou-se senso comum nas ciências sociais para além das fronteiras disciplinares. Quantos projetos de pesquisa já se leu, vindos de campos como a sociologia, políticas sociais, psicologia social e educação, em que o proponente explica que vai conduzir "entrevistas etnográficas" com uma amostra de informantes selecionados aleatoriamente, cujos dados serão processados através de um software especializado para que se produza "resultados"?

Esse procedimento, no qual "etnográfico" parece ser um substituto da moda para "qualitativo", ofende todos os princípios da investigação antropológica apropriada e criteriosa - incluindo o compromisso aberto e de longo prazo, a atenção generosa, a profundidade relacional e a sensibilidade ao contexto. E se está certo em protestar contra ele. Tem-se igualmente o direito de protestar quando aqueles que avaliam os projetos exigem, em nome da etnografia, a mesma aderência cega aos protocolos da metodologia positivista, ao demandar que se especifique, por exemplo, com quantas pessoas se pretende conversar, por quanto tempo, e como elas serão selecionadas. Contra esses parâmetros, a pesquisa antropológica está fadada a ser desvalorizada.

Mas as queixas serão em vão a menos que se consiga explicar o que se quer dizer por etnografia em termos que sejam intelectualmente defensáveis e convincentes. Não basta afirmar que a pesquisa antropológica é etnográfica porque é isso que os antropólogos fazem. Ostentar a etnografia como uma medalha de honra não irá impressionar ninguém para além do pequeno círculo encantado a que se pertence. Num momento em que tantos sentem que essa disciplina encontra-se ameaçada, empurrada para as margens onde deixou de gozar da voz pública que um dia teve, a incapacidade cada vez maior de explicar o que realmente se quer dizer por etnografia tem sido fonte de embaraços. Ainda mais quando se continua, defensivamente, a se apoiar na etnografia como aquilo que distinguiria a antropologia e justificaria sua existência enquanto disciplina, com uma contribuição distintiva. Apostar o futuro nessa areia movediça é uma estratégia deveras arriscada!

\section{O QUE É ETNOGRAFIA}

Considerem-se alguns dos termos em que o qualificador "etnográfico" aparece rotineiramente: há o encontro etnográfico, o trabalho de campo etnográfico, o método etnográfico, o conhecimento etnográfico. Há monografias etnográficas e filmes etnográficos. E agora há a teoria etnográfica! Perpassando tudo isso está o etnógrafo. Tomando essa como dimensão primária da sua identidade, parece que tudo aquilo a que o etnógrafo se dedica é, prima facie, etnográfico. Suponha-se que você reflita e escreva sobre a sua própria experiência bom, se você é um etnógrafo, então isso é autoetnografia. Considere-se que o seu papel seja fazer curadoria em um museu de artefatos coletados em diferentes partes do mundo - então isso é etnografia de museu. Mas, curiosamente, o termo não é extensivo ao que acontece dentro dos confins da academia. Até onde se sabe, nenhum dos colegas antropólogos jamais afirmou estar fazendo etnografia na sala de aula, quando trabalha com seus alunos. No ambiente de seminários, workshops e congressos, antropólogos acadêmicos falam muito sobre etnografia, mas raramente dizem estar fazendo etnografia. É como se a etnografia sempre acontecesse em outro lugar.

Volta-se a essas inconsistências mais adiante. Primeiramente, expõe-se a posição pessoal sobre o que significa etnografia. Literalmente, quer dizer: escrever sobre os povos [people]. Embora os antropólogos, normalmente, não consultem dicionários em busca de definições legítimas, outros podem fazê-lo, e eis o que encontrariam: "Uma descrição científica das raças e 
povos com seus costumes, hábitos e diferenças mútuas".1 Isso soa irremediavelmente anacrônico. Imediatamente, seria removida qualquer referência à raça. A descrição vai muito além de um simples catálogo de hábitos e costumes. Ao adensar as descrições, dando uma agência histórica real às pessoas que nelas figuram, pode-sequalificar o sentido em que estas podem ser consideradas científicas. A descrição etnográfica, pode-se dizer, é mais uma arte que uma ciência, mas não menos precisa ou verdadeira. Como os pintores holandeses do século XVII, pode-se afirmar que os etnógrafos europeus e americanos do século XX praticavam uma "arte da descrição" (ALPERS, 1983), mais através de palavras do que de linhas e cores. Este ainda é o padrão segundo o qual se avalia esse trabalho contemporaneamente.

Questões como essas já foram debatidas ad nauseam. Muito desse debate ficou conhecido através da noção de "crise da representação". Levantaram-se questões razoáveis acerca de quem tem o direito de descrever, com base em que uma descrição pode ser considerada mais verdadeira ou autorizada que outra; em que medida a presença do autor pode ou deve ser reconhecida no texto; e como o processo de escrita poderia se tornar mais colaborativo. Não se pretende requentar essas controvérsias; o foco está naquilo que não é etnográfico. Embora uma monografia escrita, na medida em que objetiva fazer uma crônica da vida e época de um povo, possa ser justificadamente qualificada como etnográfica - e o mesmo possa ser dito de um filme que compartilhe esses objetivos -, não se acredita que o termo possa ser aplicado aos encontros com as pessoas, ao trabalho de campo durante o qual estes se dão, aos métodos através dos quais são realizados, ou ao conhecimento que daí decorre. Caracterizar encontros, trabalho de campo, métodos e conhecimento como etnográficos é decididamente enganador. A autoetnografia, quando descreve-se a si mesmo, e a etnografia de museu, quando há apenas objetos em curadoria, são simplesmente oximoros. Quanto à teoria etnográfica, o argumento será que isso é tomar a antropologia de trás para frente.

\section{ENCONTRANDO O MUNDO}

Inicia-se com encontros etnográficos. Colocado de modo simples: ao se conduzir as pesquisas, houve encontros com pessoas. Conversas, perguntas, estórias foram contadas e observou-se o que elas fazem. Se se é considerado competente e capaz o suficiente, pode-se juntar a elas. Não há nada particularmente especial ou incomum nisso: é, afinal, o que as pessoas fazem o tempo todo quando se encontram. Então o que poderia distinguir

\footnotetext{
${ }^{1}$ Shorter Oxford English Dictionary, 6th ed., s. v. "ethnography", 2014.
}

um encontro etnográfico de outro que não o seja? Eis você naquilo que considera ser seu campo (o que será abordado mais adiante). Você diz às pessoas que está lá para aprender com elas. Você talvez tenha a expectativa de que elas the ensinem algo sobre suas habilidades práticas, ou que elas lhe expliquem o que pensam sobre as coisas. Você se esforça para lembrar de tudo o que observou, de tudo o que as pessoas lhe disseram, e, por via das dúvidas, registra tudo em suas notas de campo assim que possível. Poderia ser então o entusiasmo por aprender, o extenuante trabalho de memória, ou talvez as anotações subsequentes, que emprestam uma inflexão etnográfica aos seus encontros com outros?

A resposta é: não. Pois aquilo que se pode chamar de "etnograficidade" não é intrínseca aos encontros; é, antes, um julgamento lançado sobre esses encontros que transforma retrospectivamente o aprendizado, a memorização e as anotações que eles propiciam em pretextos para outra coisa. Esse propósito ulterior, invisível para as pessoas que você secretamente entende enquanto informantes, é documental. É isso que converte sua experiência, sua memória e suas notas em material - algumas vezes entendido de modo cientificista enquanto "dados" - no qual você espera poder se apoiar posteriormente durante o projeto de oferecer uma descrição. Os riscos de impostura implicados nesse etnografar de encontros, e os dilemas éticos que os acompanham, são bem conhecidos e também já foram muito debatidos. Ninguém pode acusar os antropólogos de fingir que não os vê. Não é aqui, contudo, que está o problema, mas na distorção temporal que faz com que o resultado dos encontros com as pessoas apareça como sua condição prévia. Aludindo a essa mesma distorção, Johannes Fabian (1983, p.37) fala das "tendências esquizocrônicas da antropologia emergente". Com efeito, considerar encontros como etnográficos é relegar algo que é incipiente - o que está por acontecer em relações que se desenrolam - a um passado temporal que já aconteceu. É como se, ao se encontrar outros face a face, já se desse as costas a eles, ou seja, é deixar para trás aqueles que são verdadeiros "duas caras"!

Durante um determinado período de tempo, os encontros com as pessoas são compostos e incorporados àquilo que se veio a conhecer como trabalho de campo. Portanto, as objeções levantadas contra o etnografar dos primeiros se aplicam também ao segundo. A etnograficidade não é mais intrínseca ao trabalho de campo do que aos encontros do qual este é feito. E a confusão entre etnografia e trabalho de campo é uma das mais comuns na disciplina, e especialmente insidiosa por ser raramente questionada. Reconhece-se que o campo nunca é vivido enquanto tal quando você está de fato lá, ocupando-se dos afazeres da vida quotidiana - que ele 
só emerge quando você o deixou, e começa a escrever sobre ele. Talvez o mesmo não valha para o etnográfico. Para que se seja consistente, talvez se deva remover tanto o "etnográfico" quanto o "campo" do trabalho de campo etnográfico, e referir-se simplesmente ao modo já consolidado de trabalhar: a observação participante. Como apontaram Jenny Hockey e Martin Forsey (2012), etnografia e observação participante não são a mesma coisa.

\section{OBSERVANDO A PARTIR DE DENTRO}

Observar significa ver que o acontece no entorno e, é claro, também ouvir e sentir. Participar significa fazê-lo a partir de dentro da corrente de atividades através da qual a vida transcorre, concomitante e conjuntamente com as pessoas e coisas que capturam a atenção que se dispensa a elas. Assim como o encontro, a observação participante antropológica só difere em grau daquilo que as pessoas fazem o tempo todo, especialmente as crianças. Mas as crianças têm a vida inteira pela frente para aprender. Para o antropólogo adulto, que chega como um noviço, com pouco tempo à disposição, os obstáculos são significativamente maiores. Enquanto uma maneira de trabalhar - ou talvez, uma expressão condensada do modo como todos trabalham -, a observação participante é um procedimento que se endossa plenamente. Porém, não se está certo de que se tem total ciência do quão importante e essencial é fazer o que ser faze. Nesse sentido, deseja-se avançar dois pontos. $\mathrm{O}$ primeiro diz respeito ao compromisso ontológico; o segundo será abordado na próxima seção.

Às vezes, supõe-se que participação e observação estejam em contradição. Como é possível observar e participar simultaneamente? Isso não equivaleria a nadar no rio e permanecer nas margens ao mesmo tempo? "É possível observar e participar", escreve Michael Jackson (1989, p. 51): "Sucessivamente mas não simultaneamente". Observação e participação, ele prossegue, produzem tipos diferentes de dados - objetivos e subjetivos, respectivamente. Então como compatibilizar o engajamento da participação com o distanciamento da observação? Questões como essas se fundamentam numa certa compreensão da imanência e transcendência que está profundamente ancorada nos protocolos da ciência normal, segundo os quais a existência humana dividese entre estar no mundo e conhecer $o$ mundo. A suposta contradição entre participação e observação não passa de um corolário desse divisor. É como se fosse possível aspirar à verdade sobre o mundo apenas através de uma emancipação que faz com que se desligue dele, e que provoca um estranhamento de nós mesmos (INGOLD, 2013, p.5).
Certamente, a antropologia não pode aceitar passivamente essa partilha entre conhecer e ser. Mais que qualquer outra disciplina das ciências humanas, detém os meios e a determinação para mostrar como o conhecimento emerge a partir das encruzilhadas de vidas vividas junto com outros. Como bem se sabe, esse conhecimento consiste não em proposições sobre o mundo, mas em habilidades de percepção e capacidades de julgamento que se desenvolvem no decorrer de engajamentos diretos, práticos e sensíveis com aquilo que está à volta. Isso enterra, de uma vez por todas, a falácia comum de que a observação seria uma prática exclusivamente dedicada à objetificação dos seres e coisas que comandam a atenção, e à sua remoção da esfera do envolvimento sensível com os outros. Conforme Jackson (1989, p. 51), a observação produz "dados objetivos." Nada poderia ser menos verdadeiro. Pois observar não é objetificar; é atender ${ }^{2}$ as pessoas e coisas, aprender com elas, e acompanhá-las em princípio e prática. Com efeito, não pode haver observação sem participação - ou seja, sem uma composição íntima, na percepção como na ação, entre observador e observado (INGOLD, 2000, p. 108). Assim, a observação participante $n \tilde{a} o$ é, em absoluto, uma técnica à paisana para coleta de informações das pessoas, sob o pretexto de estar aprendendo com elas. É, antes, a contemplação, em ato e palavra, daquilo que de deve ao mundo pelo próprio desenvolvimento e formação. É isso que se entende por compromisso ontológico.

\section{EDUCAÇÃo ATRAVÉS DA ATENÇÃo}

Mas praticar observação participante também é ser educado. Acredita-se, inclusive, que haja boas razões para substituir a palavra "etnografia" por "educação" enquanto desígnio primeiro da antropologia. Não se está pretendendo com isso alavancar o subcampo menor e injustificadamente negligenciado, conhecido como antropologia $d a$ educação. Insiste-se, pelo contrário, na antropologia enquanto uma prática de educação. Ou seja, uma prática dedicada ao que Kenelm Burridge (1975, p. 10) chamou de metanoia: "Uma série contínua de transformações, cada qual alterando os predicados do ser". Embora Burridge defenda a metanoia como meta da etnografia, pensa-se que ela descreve melhor a meta da educação. Jackson (2013, p. 28), que se alinha a Burridge ao pensar sua própria pesquisa realizada entre os Kuranko de Serra Leoa, reconhece: "Serra Leoa me transformou,

\footnotetext{
${ }^{2}$ N. da T.: Não há um verbo equivalente em português que abarque todos os sentidos de attend evocados por Ingold neste e em outros textos: comparecer, acompanhar, servir, cuidar, estar atento, e, finalmente, atender (a um pedido, um cliente) são alguns deles. Optou-se pelo termo "atender" como tradução padrão, mas que pode variar dependendo do contexto da frase.
} 
moldou a pessoa que sou e a antropologia que faço". Mais precisamente, é por isso que a antropologia que ele faz é uma prática de educação e não de etnografia. "Nunca pensei a minha pesquisa entre os Kuranko como elucidação de um mundo da vida único ou de uma visão de mundo estrangeira", ele admite. "Pelo contrário, era o laboratório no qual eu explorava a condição humana" (ibid.).

Com seus mentores Kuranko, Jackson estudou as condições e possibilidades de ser humano. Fazer antropologia é precisamente isso. Mas, no mesmo sentido, uma vez que ele não pretende elucidar o mundo da vida Kuranko, não se trata de etnografia. E não obstante, Jackson continua a se colocar como um etnógrafo! Num outro momento, contudo, ele se aproxima de definir seu projeto antropológico em termos educacionais: tratar-se-ia, diz ele, de "abrir novas possibilidades para pensar a experiência" (ibid, p. 88) - um processo que ele chama, seguindo o filósofo Richard Rorty, de edificação. Para Rorty, edificar é manter viva a conversação e, no mesmo sentido, resistir à afirmação de qualquer verdade final e objetiva. É abrir espaço, escreve ele, "para a sensação de encantamento que os poetas às vezes provocam encantamento de que há sim algo de novo debaixo do sol, que $n a ̃ o$ seja uma representação precisa de algo que já está lá, algo que (ao menos por hora) não pode ser explicado, e apenas precariamente descrito" (RORTY, 1980, p. 370).

Mas esse encantamento, que Rorty atribuiu ao poeta, também não estaria no cerne da sensibilidade antropológica? Como a poesia, a antropologia é uma busca pela educação no sentido original do termo, diferente do sentido que ele veio a adquirir ao ser assimilado na instituição da escola. Derivada do latim educere (de ex, "fora", mais ducere, "levar para"), a educação consistia em levar os noviços para fora, para o mundo, e não, como se entende hoje, instilar conhecimento dentro das suas mentes. Ao invés de se fixar numa posição ou propiciar uma perspectiva, a educação nesse sentido provoca um deslocamento de qualquer ponto de vista - de qualquer posição ou perspectiva que se possa adotar. Nos termos do filósofo da educação Jan Masschelein (2010a, p.278), a educação seria uma prática de exposição.

Com efeito, a observação participante consiste precisamente nisso. Convida o antropólogo noviço a se manter atento ao que os outros estão fazendo ou dizendo, ao que acontece à sua volta; a acompanhar os demais aonde quer eles vão, ficar à sua disposição, não importando o que isso implique e para onde o leve. Fazê-lo pode ser perturbador, e implicar riscos existenciais consideráveis. É como lançar o barco na direção de um mundo ainda não formado - um mundo no qual as coisas ainda não estão prontas, são sempre incipientes no limiar da emergência contínua. Comandados não pelo dado, mas pelo que está a caminho de sê-lo, deve-se estar preparado para esperar [wait] (MASSCHELEIN, 2010b, p.46). Com efeito, esperar pelas [wait upon] coisas é precisamente o que se quer dizer por atender [attend $]$ a elas. ${ }^{3}$

\section{SOBRE INTERSUBJETIVIDADE E CORRESPONDÊNCIA}

Como bem sabe qualquer antropólogo, a observação participante envolve muita espera. Lançada na correnteza do tempo real, a esta compõe o movimento prospectivo da própria percepção e ação que se tem com os movimentos de outros, como linhas melódicas são compostas no contraponto musical. Propõe-se o termo correspondência para designar essa composição de movimentos que, à medida que se desenrolam, respondem continuamente uns aos outros (INGOLD, 2013, p. 105-8). Não se entende por isso um alinhamento preciso nem um simulacro daquilo que se encontra nos acontecimentos à volta. Não tem nada a ver com representação ou descrição. Trata-se, pelo contrário, de responder a esses acontecimentos por meio das próprias intervenções, questões e respostas em outras palavras, viver atencionalmente com outros. A observação participante é uma prática de correspondência nesse sentido. Entretanto, quando tomada nos termos esquizocrônicos da etnografia, a correspondência reaparece sob a roupagem bem diferente da "intersubjetividade". E, seguindo Edmund Husserl, intersubjetividade é viver com outros não atencionalmente, mas intencionalmente (DURANTI, 2010; JACKSON, 2013, p. 5).

No que concerne à intersubjetividade etnográfica, pergunta-se: seria ela dada enquanto condição existencial, ou alcançada enquanto resultado comunicativo? Questão irrespondível, posto que enredada no mesmo movimento através do qual etnografar encontros transforma resultados finais em condições iniciais. Mas, com a correspondência, essa questão não se coloca. A intersubjetividade não é nem dada, nem alcançada - está sempre em emergência. Certamente não é uma relação entre um sujeito (tal qual o antropólogo em pessoa) e outros, como sugere o prefixo inter; ela prossegue ou se desdobra ao longo de caminhos que se cruzam. E, ao seguirem vivendo, as pessoas e coisas não se encontram já lançadas no mundo - como sugere o sufixo jet -, mas estão sendo lançadas. ${ }^{4}$ Elas não são nem sujeitos, nem objetos, e tampouco híbridos de sujeitos-objetos. São, antes, verbos. Isso vale tanto para

\footnotetext{
3 N. da T.: Tanto no caso do verbo attend como de wait [upon], há uma confluência, pouco marcada no português, entre os sentidos de "esperar" e de "servir", "estar atento", "acompanhar" e outros elencados na nota de rodapé anterior. Attend tem o sentido de esperar no inglês arcaico (assim como no francês attendre), e o phrasal verb wait upon, que Ingold usa de modo quase intercambiável com attend, não por acaso tem a raiz wait (esperar). Um bom exemplo em que os dois sentidos se encontram unidos é o termo em inglês para garçon, waiter.

4 N. da T.: No original, in the throwing. Provavelmente, uma referência ao Geworfenheit, de Heidegger.
} 
humanos como para seres de outros tipos. Com efeito, humanos não são seres, mas "devires" (INGOLD e PALSSON, 2013). Onde quer que estejam, os humanos estão humanando [humaning]. Ou seja, eles estão correspondendo - como fazem os escritores de cartas quando transcrevem seus pensamentos e sentimentos, e esperam por respostas. Vivem vidas emaranhadas umas nas outras, que se estendem indefinidamente. As "pontas soltas" que Johannes Fabian (na seção temática da revista $H a u$, na qual este texto foi originalmente publicado) encontrou na intersubjetividade são precisamente os fios que se emaranham na correspondência, e que permitem à vida seguir seu rumo. Num mundo interconectado, onde tudo e todos já se encontrassem unidos e todas as linhas levassem de $\mathrm{A}$ até $\mathrm{B}$, nenhuma vida seria possível.

Praticar a observação participante é, portanto, juntarse em correspondência àqueles com quem se aprendeu ou entre os quais se estudou, num movimento que, ao invés de voltar no tempo, segue em frente. Aqui está o propósito, dinâmica e potencial educacional da antropologia. Enquanto tal, é o oposto da etnografia, cujos objetivos descritivos e documentais impõem suas próprias finalidades a essas trajetórias de aprendizado, transformando-as em exercícios de coleta de dados destinados a produzir "resultados," normalmente na forma de artigos ou monografias. Isso nos traz de volta à questão do método. É comum que o termo etnográfico seja inserido antes tanto de "método" quanto de "trabalho de campo" - o que normalmente implica alguma forma de observação participante. Já se mostrou que o etnografar a posteriori da observação participante solapa tanto o compromisso ontológico que ela implica quanto seu propósito educacional. Mas ainda restam questões relativas à noção de método. Dado que a observação participante e a etnografia são coisas totalmente diferentes - sendo a primeira uma prática de correspondência e a segunda, uma prática de descrição -, podem ser ambas consideradas como método?

\section{UMA MANEIRA DE TRABALHAR}

Isso depende, é claro, do que se entende por método. Talvez se possa caracterizar a observação participante como uma maneira de trabalhar. É provavelmente isso que C. Wright Mills (1959, p.216) tinha em mente quando escreveu seu famoso ensaio sobre o trabalho intelectual, no qual ele insistiu na indistinção entre a teoria de uma disciplina e seu método - sendo ambos aspectos indissociáveis da prática de um ofício. Se o método da antropologia envolve um trabalho prático com pessoas e materiais, então sua disciplina está no engajamento observacional e educação perceptual que permite ao praticante acompanhar e responder àquilo que acontece. Mas isso está longe do que se convenciona chamar de método segundo os protocolos da ciência normal, em que implementá-lo é executar uma sequência de passos preestabelecidos e regulados rumo à consecução de uma meta determinada. Pois os passos da observação participante, como os da própria vida, dependem das circunstâncias, e não avançam rumo a um fim preestabelecido. E envolvem modos de levar a vida e de ser por ela levado, de viver uma vida junto com outros - humanos e não humanos - que reconhecem o passado, atentam para as condições do presente e se abrem especulativamente a possibilidades futuras.

Então o que é a etnografia sensu stricto? Seria um método? Enquanto ofício que envolve escrever sobre as pessoas, a etnografia sem dúvida tem seus métodos, como sugerido por Mill. Mas que ela seja um método, aplicado com vistas a uma finalidade maior, é algo altamente questionável. Argumenta-se firmemente na negativa. A etnografia tem, decerto, um valor em si mesma, e não por ser um meio para algo que está além dela. Não se tem de buscar uma justificativa para ela em outro lugar. Que outro bem maior poderia haver ao qual a etnografia supostamente deveria sua existência? Um tradicionalista poderia responder: a antropologia comparativa. Houve um momento em que se dizia que os estudos etnográficos deveriam ser tratados como compêndios de dados empíricos sobre as diversas sociedades e culturas do mundo, que poderiam então ser usados para testar as generalizações teóricas (SPERBER, 1985, p.10-11). Ainda hoje se insiste em reunir estudos feitos aqui e ali, entre as capas de volumes editados, na esperança de que insights mais gerais eventualmente emerjam. Porém, não apenas a escrita etnográfica é toscamente desvalorizada ao ser reduzida a "dados", como também já se mostrou falaciosa a ideia de que universais sejam algo mais que abstrações feitas pelas pessoas. Antropologia e etnografia são de fato coisas diferentes, como já se indicou; mas essa distinção não se sobrepõe a uma diferença entre o geral e o particular, ou entre o trabalho comparativo-teórico na escrita e a coleta de dados empíricos no campo. A etnografia não é um prelúdio para a antropologia, e nem o trabalho de campo uma preliminar da escrita. Quando muito, seria o inverso. O etnógrafo escreve; o antropólogo - um observador correspondente - desenvolve o seu pensar no mundo (INGOLD, 2011, p. 241-243).

\section{UMA CONVERSA SOBRE A VIDA HUMANA}

Os frutos desse pensar são o que se tende a chamar de "conhecimento". Às vezes, fala-se de conhecimento antropológico; outras, de conhecimento etnográfico. Litros de tinta já foram gastos discutindo o que seria esse conhecimento. Hoje, há consenso razoável em 
torno da ideia de que o conhecimento não é construído a partir de fatos que simplesmente estão lá, esperando para serem descobertos e organizados de acordo com os conceitos e categorias que se tem; pelo contrário, este cresce e é nutrido através das relações com outros. Não se recolocamos argumentos que sustentam essa visão, mas se parte deles. Como Bob White e Kiven Strohm afirmaram em seu prefácio na seção temática da revista $\mathrm{Hau}$, na qual esse texto foi originalmente publicado, o conhecimento é coproduzido. Mas é aqui que se volta à observação anterior de que, para a maioria dos colegas que se denominam intercambiavelmente antropólogos e etnógrafos, a prática de gerar ou coproduzir conhecimento que eles chamariam de "etnográfico" parece se deter nos muros da academia. Dentro desses muros, eles falam o tempo todo sobre etnografia, entre si e para seus estudantes, e, é claro, escrevem etnografias - mas não a fazem. Então, conhecimento coproduzido com informantes seria etnográfico, mas conhecimento coproduzido com estudantes, não.

Não se está sugerindo que se deva etnografar os estudantes ou os colegas da academia. Lá se está para trabalhar com eles, e não para fazer estudos sobre eles. Mas pode-se desafiar aqueles que insistem em usar o termo etnográfico para descrever o conhecimento que cresce a partir de seus engajamentos colaborativos (ou correspondência) com as pessoas entre as quais eles trabalham. O que explica por que não consideram igualmente apropriado descrever nesses termos o conhecimento nutrido a partir da sua correspondência com colegas e estudantes. Não seria porque, não obstante os protestos ao contrário, eles permaneceriam cúmplices da reprodução de uma distinção perniciosa entre aqueles a partir dos quais e com os quais se aprende, respectivamente, dentro e fora da academia? Decerto, quando se busca uma educação com os grandes acadêmicos, não é para passar o resto da vida descrevendo ou representando suas ideias, visões de mundo, ou filosofias. É para aperfeiçoar as faculdades perceptuais, morais e intelectuais para as tarefas críticas que vêm a seguir. Mas se é esse o caso, e se - como se argumentou - praticar antropologia é ser educado dentro e fora da academia, então o mesmo deve valer para as correspondências com os interlocutores "não acadêmicos". Conhecimento é conhecimento, onde quer que ele cresça, e assim como o propósito ao adquiri-lo dentro da academia é (ou deveria ser) educacional e não etnográfico, assim deve ser também fora da academia.

Um exemplo do tipo de distorção a que se refere pode ser encontrado em um editorial recente da revista Anthropology Today, de autoria de Catherine Besteman e Angelique Haugerud. Trata-se de um convite para a antropologia pública. É claro, como elas mesmas reconhecem, que nunca houve uma antropologia que não fosse pública, "no sentido de que nosso forte disciplinar é a etnografia, através da qual nós cuidadosamente exploramos as visões de nossos interlocutores de pesquisa" (BESTEMAN e HAUGERUD, 2013, p.2). Pode-se concordar que a exploração cuidadosa, até mesmo forense, de ideias é um desiderato primordial do trabalho acadêmico. Mas fazê-lo em nome da etnografia é justamente neutralizar o desafio que o engajamento crítico com outros modos de fazer e conhecer pode colocar para a opinião pública. Por quê? Porque, ao etnografar esses modos, a prioridade é deslocada do engajamento para o relato, da correspondência para a descrição, da coimaginação de futuros possíveis para a caracterização daquilo que já passou. É, poder-se-ia dizer, olhar do lado errado do telescópio. Ao invés de acionar a visão propiciada pela educação para iluminar e alargar o mundo, o etnógrafo retira suas observações do mundo ao tomar os modos dos outros como objeto de escrutínio. Quem ousaria fazer o mesmo com os mentores e pares na academia? Pois, além de seus muros, esse procedimento desleal não é apenas rotina; chega-se mesmo a ostentá-lo como o ponto forte disciplinar!

\section{Antropologia Ao AVESSo}

É decerto preocupante que a antropologia tenha perdido sua voz pública, ou que seja raramente ouvida. Praticantes de outros ofícios, frequentemente com agendas imprudentes, populistas ou fundamentalistas, estão ávidos por preencher esse vácuo. No seu afã por alimentar o preconceito popular, alguns têm até simulado credenciais antropológicas. A incapacidade que se tem de coibir essas improbidades é um sintoma do retraimento da antropologia. No seu manifesto pela renovação da teoria etnográfica, Giovanni da Col e David Graeber (2011, p.ix) chegam a lamentar que a antropologia esteja, em seu dilema contemporâneo, "cometendo um tipo de suicídio intelectual.” Mas isso se deve, como eles alegam, a uma carência de insights originais? Teria sido a virada da etnografia para a filosofia - especificamente aquela advinda da Europa continental - a responsável por colocar a disciplina no caminho da autodestruição?

Pensa-se que não. Para começar, não se compartilha a avaliação pessimista de da Col e Graeber sobre a antropologia contemporânea. Não há escassez de insights originais. Quando comparada à maioria das outras disciplinas, a antropologia tem na verdade impressionado por sua originalidade. Mas se há algo que impede que os insights antropológicos exerçam os efeitos transformativos mais amplos que se espera deles, é o recurso constante à etnografia. "O particularismo etnograficamente orientado", notou Stuart McLean (2013, p.66-67), "tornou-se não apenas a configuração padrão de boa 
parte da pesquisa e da escrita antropológica atuais... como também a base para muitos argumentos sobre a relevância da disciplina para a compreensão dos processos sociais contemporâneos". McLenan é cético quanto a essa "visão quase universalmente compartilhada sobre a antropologia" - e concorda-se com o autor. Pois, ao invés de incrementar sua relevância social, parece que o apelo à etnografia tem mantido a antropologia refém do estereótipo popular (e não sem fundamento) do etnógrafo, enquanto aquele que se limita a descrever retrospectivamente vidas que estão sempre em vias de desaparecer.

Mas o que é então esse estranho híbrido de pragmatismo e filosofia que atende pelo nome de teoria etnográfica? De certo modo, essa questão remonta à antropologia enquanto "filosofia com pessoas dentro": um empreendimento energizado pela tensão entre investigação especulativa sobre o que a vida poderia ser e um conhecimento, enraizado na experiência prática, sobre o que a vida é para as pessoas de diferentes tempos e lugares (INGOLD, 1992, p. 696). Mas já se mostrou que, ao ser etnografada, essa experiência é esquizocronicamente colocada no momento mesmo em que é vivida. Já a teoria se torna um domínio no qual os etnógrafos, ao deixarem seus respectivos locais de campo, comerciam os insights que trouxeram consigo. Como connoisseurs de arte exótica, eles esperam colocar seus tesouros em exposição, e extrair valor da sua comparação e justaposição. No museu da teoria etnográfica, conceitos-objetos como totem, mana e šaman, trazidos de três continentes diferentes, são colocados lado a lado na prateleira, à espera das atenções de um acadêmico virtuoso que as transforme magicamente em algum tipo de "homonimidade disjuntiva" (DA COL e GRAEBER, 2011, p.viii).

Com efeito, etnografia e teoria lembram os dois arcos de uma hipérbole, que lançam seus raios em direções opostas, iluminando as superfícies da mente e do mundo, respectivamente. Elas se dão as costas, e entre as duas reina a escuridão. Mas e se cada arco invertesse sua orientação, para abraçar o outro numa elipse abrangente, intensamente iluminada? Não se teria nem etnografia nem teoria, e tampouco uma combinação das duas. E, sim, o campo não dividido, intersticial da antropologia. Se a teoria etnográfica é a hipérbole, a antropologia é a elipse. Pois ao se virar, a etnografia não é mais etnografia, mas as correspondências educacionais da vida real. E quando a teoria se vira, ela não é mais teoria, mas uma imaginação nutrida através de engajamentos observacionais com o mundo. A ruptura entre realidade e imaginação - uma ligada ao fato, a outra à teoria - tem sido fonte de muita confusão na história da consciência. Precisa ser reatada. E é sobretudo tarefa da antropologia fazê-lo. Ao clamar pelo fim da proliferação da etnografia, não se está pedindo mais teoria. $\mathrm{O}$ apelo é por um retorno à antropologia.

\section{REFERÊNCIAS}

ALPERS, Svetlana. The art of describing: Dutch art in the seventeenth century. London: Penguin, 1983.

BESTEMAN, Catherine; HAUGERUD, Angelique. The desire for relevance. AnthropologyToday, v. 29, n. 6, p. 1-2, 2013.

BURRIDGE, Kenelm. Other people's religions are absurd. In explorations in the anthropology of religion: essays in honour of Jan Van Baal, edited by E. A. VAN BEEK, Walter and SCHERER, J. H. The Hague: Martinus Nijhoff, 1975. p. 8-24.

DA COL, Giovanni; GRAEBER, David. Foreword: The return of ethnographic theory. Hau: Journal of Ethnographic Theory, v. 1, n. 1, p. vi-xxv, 2011. https:/doi.org/10.14318/hau1.1.001

DURANTI, Alessandro. Husserl, intersubjectivity and anthropology. Anthropological Theory, v. 10, n. 1, p. 1-20, 2010. https:/ doi.org/10.1177/1463499610370517

FABIAN, Johannes. Time and the other: how anthropology makes its object. New York: Columbia University Press, 1983.

HOCKEY, Jenny; FORSEY, Martin. Ethnography is not participant observation: reflections on the interview as participatory qualitative research. In the interview: an ethnographic approach, edited by Jonathan Skinner. New York: Berg, 2012. p. 69-87.

INGOLD, Tim. Editorial. Man, New Series, v. 27, n. 4, p. $693-$ 696, 1992

The perception of the environment: Essays on livelihood, dwelling, and skill. London: Routledge, 2000.

Being alive: Essays on movement, knowledge, and description. Abingdon: Routledge, 2011.

Making: Anthropology, archaeology, art and, architecture. Abingdon: Routledge, 2013.

INGOLD, Tim; PÁLSSON, Gísli (eds.). Biosocial becomings: integrating social and biological anthropology. Cambridge: Cambridge University Press, 2013.

JACKSON, Michael. Paths toward a clearing: radical empiricism and ethnographic inquiry. Bloomington, IN: Indiana University Press, 1989.

Essays in existential anthropology. Chicago, IL: University of Chicago Press, 2013.

MASSCHELEIN, Jan. The idea of critical e-ducational research - e-ducating the gaze and inviting to go walking. In the possibility/impossibility of a new critical language of education, edited by Ilan Gur-Ze'ev. Rotterdam: Sense Publishers, 2010a. p. 275-291.

E-ducating the gaze: the idea of a poor pedagogy. Ethics and Education, v. 5, n. 1, p. 43-53, 2010b. https:/doi.org/ $10.1080 / 17449641003590621$

MACLEAN, Stuart. All the difference in the world: liminality, montage, and the reinvention of comparative anthropology. In: Transcultural montage, edited by Christian Suhr and Rane Willerslev. New York: Berghahn, 2013, p. 58-75.

MILLS, C. Wright. The sociological imagination. New York: Oxford University Press, 1959.

RORTY, Richard. Philosophy and the mirror of nature. Princeton, NJ: Princeton University Press, 1980.

SPERBER, Dan. On anthropological knowledge: three essays. Cambridge: Cambridge University Press; Paris: Maison des Sciences de l'Homme, 1985.

Submetido em 25/08/2015

Aprovado em 22/02/2016 